\title{
Conceptual Model for Urban Interventions in Historic Cities based on Space Syntax
}

\author{
Josna Raphael.P.
}

\begin{abstract}
Urbanism today is a synthesis of inheritance, prevalence and futurism. As our inheritance struggles with the rapid transformations and anxiously waits for the future, their conservation becomes an issue related to our cognizance of the genuine relations between tangible and intangible properties. While urban development strategies enormously emphasis the issues on sustainability, social balance, public realm, environment and heritage, the space proxemics of cities are very often ignored. This model is designed in a way that combines analytical techniques of space syntax and cultural context for an objective enquiry into user precise space proxemics of the city and scientifically states the spatial configuration as visible spatial rules or principles of urbanism in the traditional urban cores, thereby evolving a rational approach towards urban interventions. This model caters both for conservation studies and as well for rejuvenation of existing built environments or to design new urban centers for developing traditional urban cores of any city. The model has its application for urban interventions in the chosen area with quantified syntactic parameters for their spatial configuration. This resulted in both cases improving and depriving the culture-precise-human-predilections about space proxemics affecting cultural integration values.
\end{abstract}

Keywords : Historic Cities, Space Syntax, Culture, Urban Interventions

\section{INTRODUCTION}

Cultural integration in urban environment transpires through events designed to promote the reach of products and practices inherent with cultural strategies of urban redevelopment and 'regeneration' and also by way of functional events conducted to enhance social life by utilizing public spaces. How can algorithms make both planning and urban design more generative and adaptive process that favors citizens than project developers or investors? Even while asserting their significance, this paper delivers a conceptual model which dialogues across and between urbanism, spatial theory and cultural practice developing for itself considerable potential to inspire as well as develop critical approaches to cities.

Be it conservation, redevelopment or rejuvenation all are urban interventions. Since all models are simplifications of reality there is always a trade-off as to what level of detail is included in the model.

Revised Manuscript Received on February 05, 2020.

* Correspondence Author

Dr. Josna Raphael. P., Professor, School of Architecture, Government Engineering College, Thrissur, Kerala, India, email.id:josnaraphaelp@gmail.com

(C) The Authors. Published by Blue Eyes Intelligence Engineering and Sciences Publication (BEIESP). This is an open access article under the CC BY-NC-ND license (http://creativecommons.org/licenses/by-nc-nd/4.0/)

\section{METHODOLOGY}

The components used in the conceptual model for urban interventions has spatial configuration parameters using space syntax techniques. With the given model two cases of urban interventions are tested with the cultural capital of Kerala, Thrissur temple town by simulating the model. The first test is by adding two networks which decreases the existing integration value of the culturally integrated networks which reduces the cultural significance of the town. The second simulation is by adding a network which increases the integration value of the culturally integrated networks' adaptive process that works in the interest of citizens thereby improving the cultural significance of the temple town.

\section{STRUCTURE OF THE CONCEPTUAL MODEL FOR URBAN INTERVENTIONS}

Providing a method that facilitates in maintaining the cultural integration of historical cities during urban morphological interventions like addition of new networks, nodes, centers etc. is what the model intends to realize. The feature of the model is its exclusive applicability to culturally integrated historic urban cores while its design principles are limited to spatial configuration applying space syntax techniques.

The conceptual model as shown in the fig. 1 has three phases. First comes the necessity to study morphological evolution of the historic city with the cultural context both physically as well as quantitatively. The relevance of cultural significance of urban core with respect to the existing urban social structure need explored using axial map analysis as well as isovist field analysis[1]. If found relevant the model proceeds to the second phase.

The second phase has two parts. First is quantification of the urban morphology using spatial configurational parameters. Second is identification of culturally integrated urban artifacts, networks and spaces by overlapping with the configurational parameters. In this stage the quantification has to be recorded based on rank ordering. The first order integration parameters of the culturally integrated streets and nodes can be recorded as " $\mathrm{A}$ ".

The third phase is the urban model simulation by adding new streets or nodes. In this stage the first order integration parameters of the newly added streets or nodes can be recorded as "B". While adding the new network or centers, the existing urban system gets redefined as well.

The new values of the first order integration parameters of the existing culturally integrated streets and nodes can be recorded as "A1".

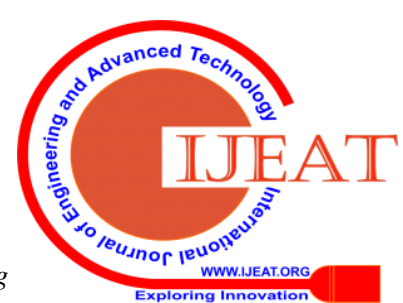


While adding a new network or node the existing primary integration values of the culturally integrated core based on the rank ordering should not go down adversely affecting the cultural relevance or the cultural definition of the urban core. Now the model can be tested for the given conditions such as $\mathrm{B}$ is less than A1 and A1 is more than or equal to A which maintains the culture precise human preferences of the urban core. If the newly added streets adversely affect the culturally integrated urban core by ' $\mathrm{B}$ ' being higher and ' $A 1$ ' being lower the interventions need to be reworked to attain the given conditions for the culturally integrated urban core for the social system in relation with the culture.

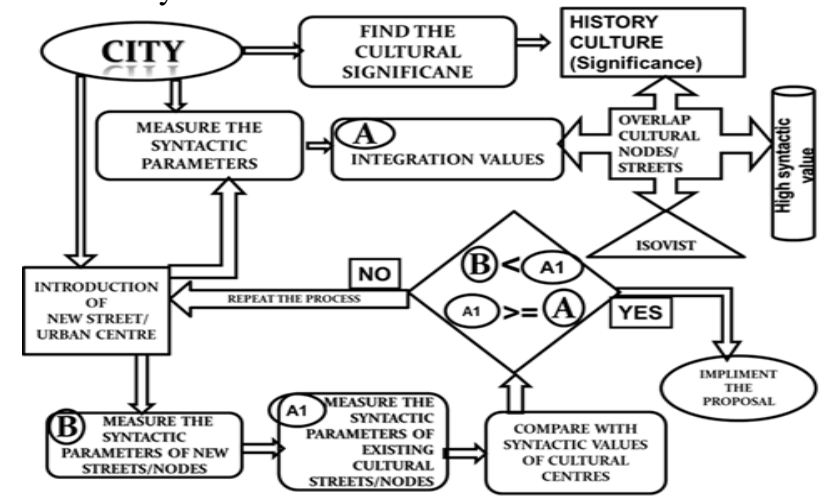

Fig 1: Conceptual Model For Urban Interventions In Historic Cities

\section{MODEL TESTING 1}

In the case of Thrissur, east fort and west fort are two major nodes in the eastern and western axis simultaneously. The simulation of the model is done by adding a new central axis connecting the east fort and west fort passing through the central core of the city as well as the major cultural nodes and squares of Thrissur. Another one is by the introduction of new outer ring road in Thrissur town connecting major national highways as shown in fig.2. As shown in fig.3 the new central axis is passing through the main Thrissur Pooram event as well.

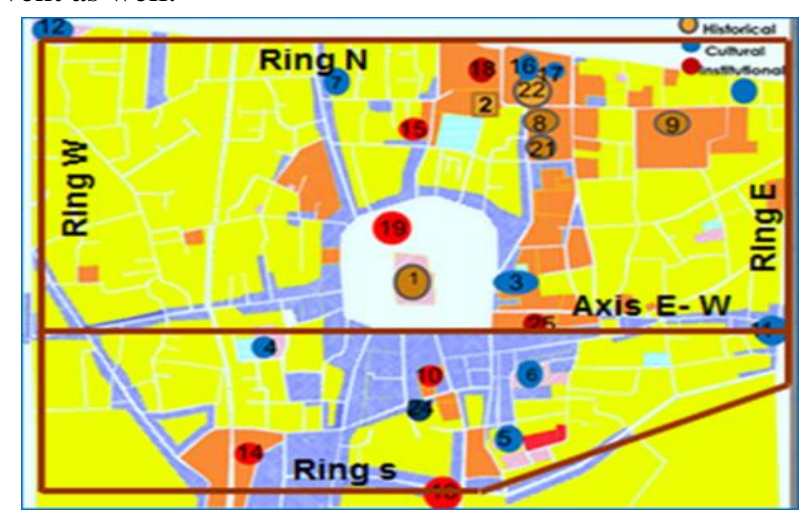

Fig 2: Base map showing the major Historical,

Cultural, and Institutional locations with the new introduced Outer ring road and central axis

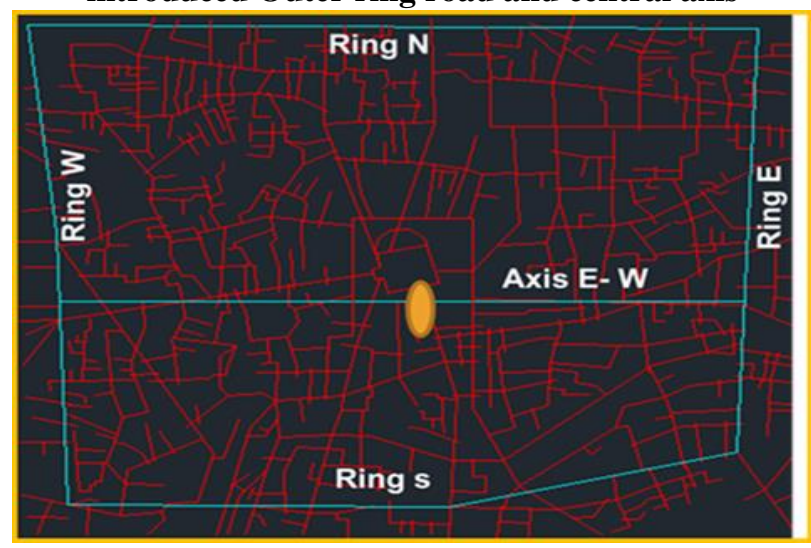

Fig 3: Axial line map showing new introduced Outer ring road and central axis

Table 1 Syntactic parameters showing B $>$ A1

\begin{tabular}{|c|c|c|c|c|c|}
\hline & $\begin{array}{l}\text { Network } \\
\text { streets }\end{array}$ & & $\begin{array}{c}\text { Global } \\
\text { Integration Rn }\end{array}$ & $\begin{array}{c}\text { Local } \\
\text { Integration } \\
\text { R3 } \\
\end{array}$ & $\begin{array}{c}\text { NACH } \\
\text { at } \\
300 \\
\text { Radii } \\
\end{array}$ \\
\hline \multirow{5}{*}{ 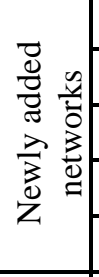 } & Axis E- W & \multirow[b]{5}{*}{ B } & 1.8148 & 3.5554 & 0.5647 \\
\hline & Ring N & & 1.708 & 3.2651 & 0.588 \\
\hline & Ring $\mathrm{s}$ & & 1.6687 & 3.0783 & 0.2988 \\
\hline & Ring E & & 1.7898 & 3.2501 & 0.6553 \\
\hline & Ring W & & 1.6839 & 3.667 & 0.3792 \\
\hline \multirow{8}{*}{ 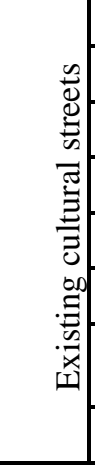 } & M G Road & \multirow[b]{8}{*}{ A1 } & 1.6391 & 2.2498 & 0.2173 \\
\hline & Round N & & 1.4705 & 2.5685 & 0.1481 \\
\hline & Round S & & 1.3287 & 2.3478 & 0.3241 \\
\hline & Round E & & 1.6271 & 2.8243 & 0.1353 \\
\hline & Round W & & 1.3676 & 2.4225 & 0.137 \\
\hline & M O Road & & 1.4807 & 2.2018 & 0.0652 \\
\hline & $\begin{array}{l}\text { Shornur } \\
\text { Road } \\
\end{array}$ & & 1.3625 & 2.4225 & 0.137 \\
\hline & High Road & & 1.4021 & 2.441 & 0.0888 \\
\hline
\end{tabular}


After the new intervention as we can see in table 1 the new integration values of existing major cultural networks (A1) have gone down compared to the integration values $(B)$ of the newly added road networks.

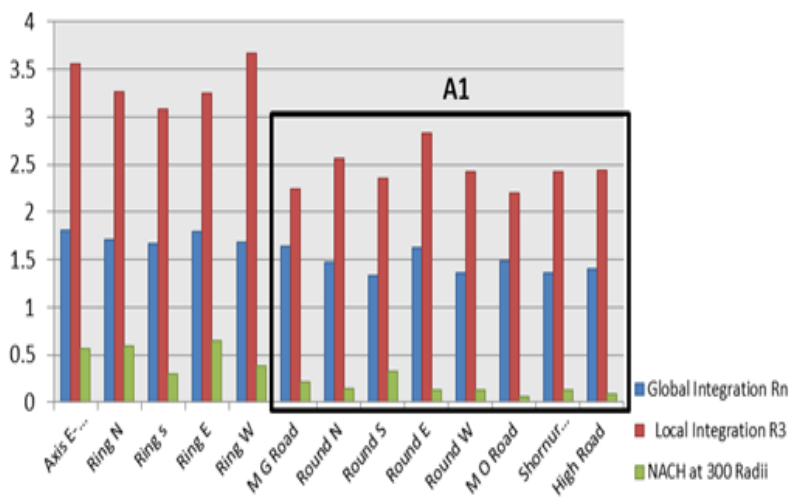

Fig 4: Syntactic parameters showing B $>$ A1
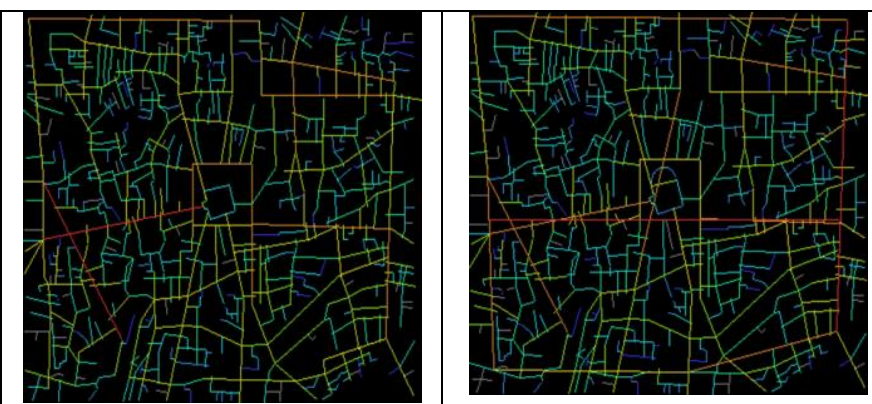

Existing Local Integration R3

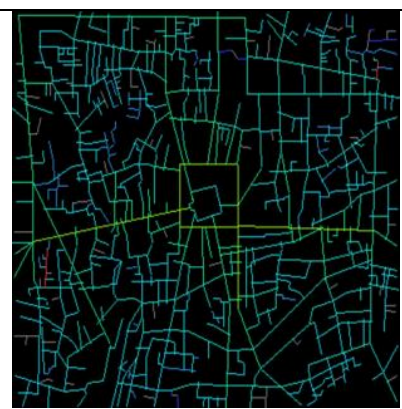

Existing Global Integration Rn

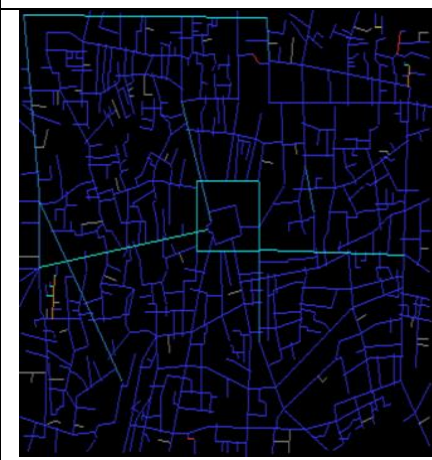

Existing NACH at 300 Radii

Fig 5: Axial map showing the syntactic parameters of Test1

And also the existing high integration values of cultural street network has gone down from the existing values which is the case of $\mathrm{A} 1<\mathrm{A}$ is shown in fig. 4 and also given in table 2.

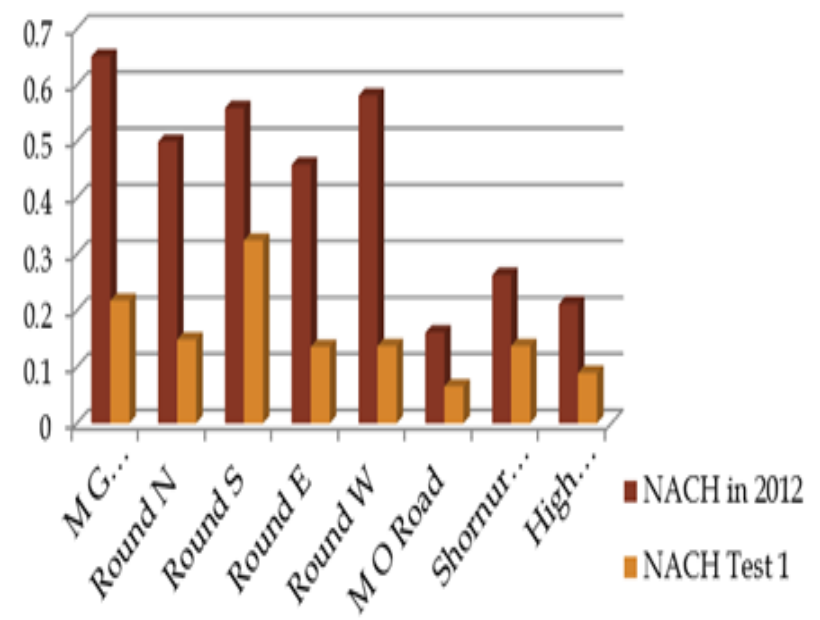

Fig 6: Comparative analysis of Normalised Angular Choice at Radii 300 of major historic, cultural streets showing A>A1

The spatial positions of individual cultural routes with Angular radii 300 reflect their spatial relationships and hierarchies in neighborhood, district, and city. Normalised angular choice in space syntax literature calculates the number of shortest paths overlap between all nodes in the graph and is implemented in depth map. Analytic experience of NACH suggests that high values indicate general thresholds for different types of activity to establish themselves in urban grids [2]. Test 1 clearly indicate that the normalised angular choice of all the major historic, cultural centers have gone down from the existing values which reduces threshold for different cultural activities of the people for the cultural spaces in Thrissur.

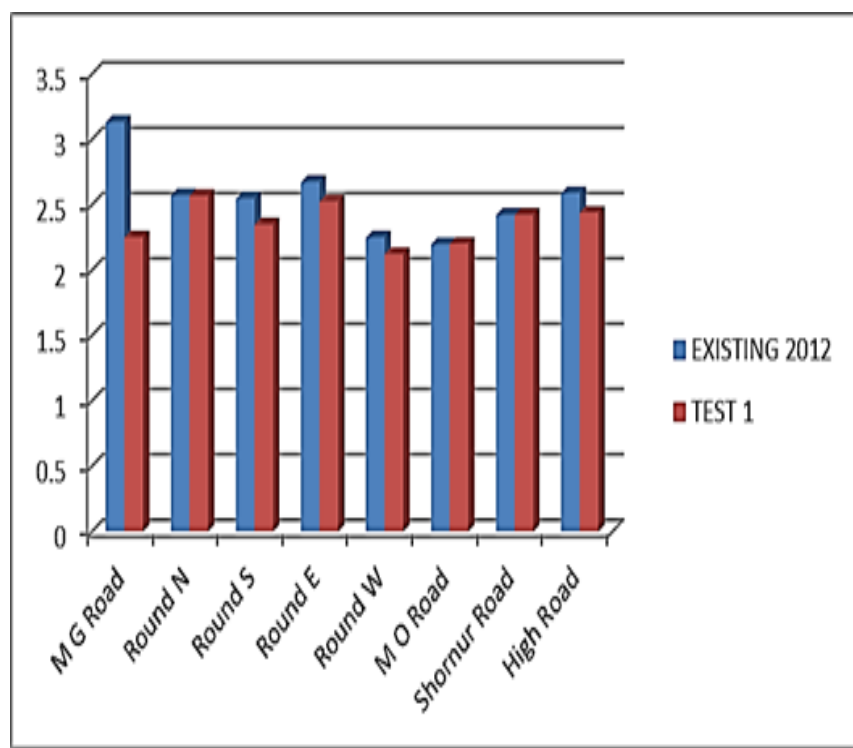

Fig 7: Comparative analysis of R3- Local Integration values of major historic, cultural street showing $\mathrm{A}>\mathrm{A1}$

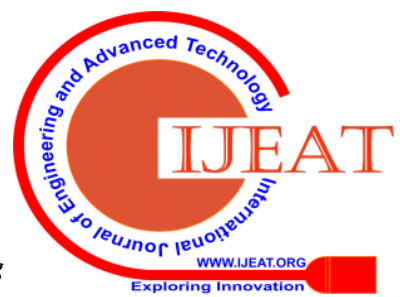


Table 2. Syntactic parameters showing A1<A

\begin{tabular}{|c|c|c|c|c|c|c|c|c|c|}
\hline \multicolumn{2}{|c|}{ Syntactic Parameters } & $\begin{array}{l}\text { MG } \\
\text { Road }\end{array}$ & $\begin{array}{l}\text { Round } \\
\text { N }\end{array}$ & $\begin{array}{l}\text { Round } \\
\mathrm{S}\end{array}$ & $\begin{array}{c}\text { Round } \\
\mathrm{E}\end{array}$ & $\begin{array}{c}\text { Round } \\
\mathrm{w}\end{array}$ & $\begin{array}{l}\text { MO } \\
\text { Road }\end{array}$ & $\begin{array}{c}\text { Shornur } \\
\text { Road }\end{array}$ & $\begin{array}{l}\text { High } \\
\text { Road }\end{array}$ \\
\hline $\begin{array}{c}\text { Global } \\
\text { Integration } \mathrm{Rn} \\
\end{array}$ & \multirow{3}{*}{$\mathbf{A}$} & 1.6912 & 1.5151 & 1.3446 & 1.6475 & 1.3889 & 1.5128 & 1.3949 & 1.4739 \\
\hline $\begin{array}{l}\text { Local } \\
\text { Integration R3 }\end{array}$ & & 3.1324 & 2.5706 & 2.5451 & 2.6729 & 2.2495 & 2.1973 & 2.4225 & 2.5883 \\
\hline $\begin{array}{c}\text { NACH } \\
\text { At } 300 \text { Radii }\end{array}$ & & 0.6507 & 0.4994 & 0.5591 & 0.4588 & 0.5811 & 0.1608 & 0.2628 & 0.2117 \\
\hline $\begin{array}{c}\text { Global } \\
\text { Integration Rn }\end{array}$ & \multirow{3}{*}{ A1 } & 1.6391 & 1.4705 & 1.3287 & 1.6271 & 1.3676 & 1.4807 & 1.3625 & 1.4021 \\
\hline $\begin{array}{c}\text { Local } \\
\text { Integration R3 }\end{array}$ & & 2.2498 & 2.5685 & 2.3478 & 2.6243 & 2.1225 & 2.2018 & 2.4225 & 2.441 \\
\hline $\begin{array}{c}\text { NACH } \\
\text { At } 300 \text { Radii }\end{array}$ & & 0.2173 & 0.1481 & 0.3241 & 0.1353 & 0.1370 & 0.0652 & 0.1370 & 0.0888 \\
\hline
\end{tabular}

\section{MODEL TESTING 2}

The second test of the model is done by introducing a new heritage street connecting historic, cultural, religious centers of Thrissur urban core making it more integrated with culture.

The new street network is shown in Fig.8 and Fig.9.

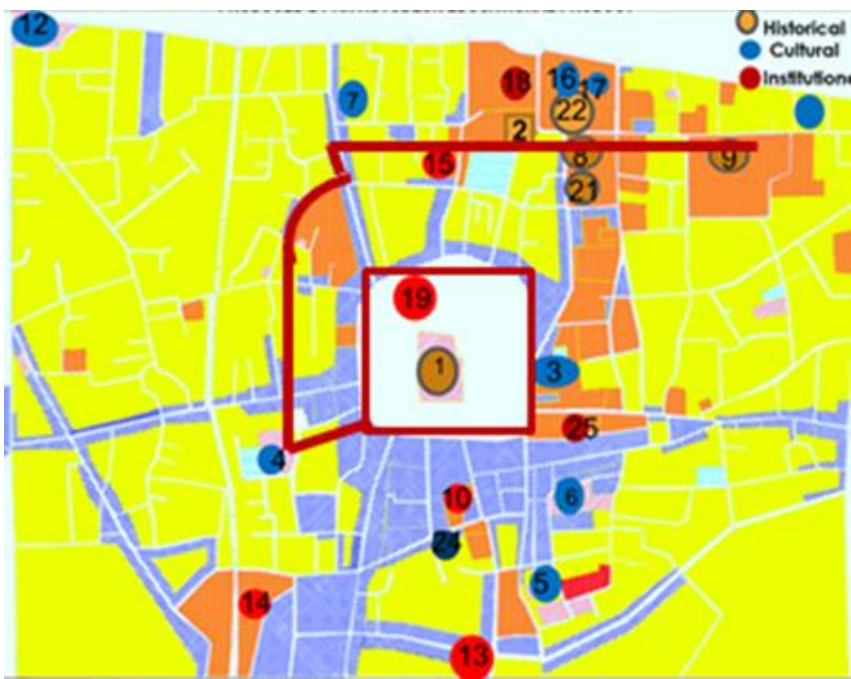

Fig 8. Base map showing the major Historical, Cultural, and Institutional locations with the new introduced Heritage Street in Thrissur

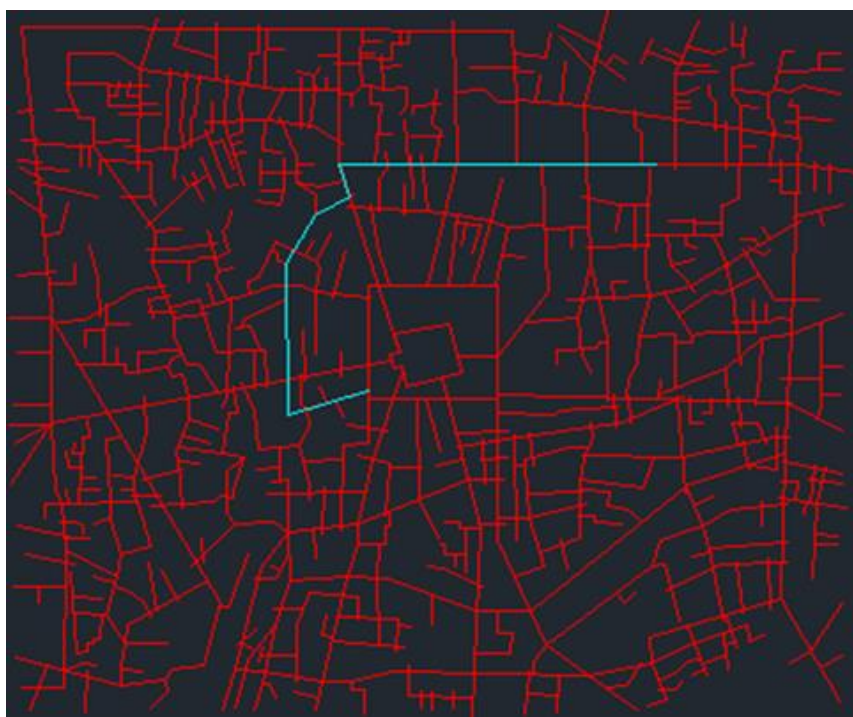

Fig 9: Axial line map showing new introduced Heritage

\section{Street in Thrissur}

After the new intervention as we can see in table 3 the new integration values of existing major cultural networks (A1) are still higher when compared to the integration values (B) of the newly added road networks.

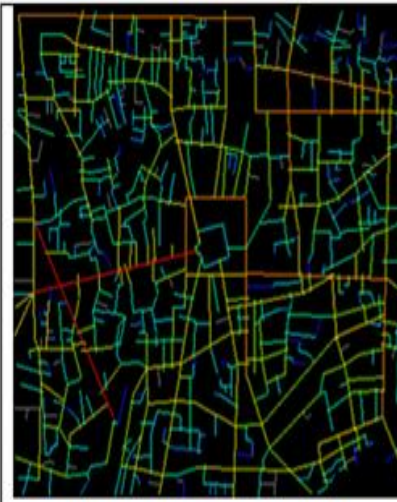

Existing Local Integration R3

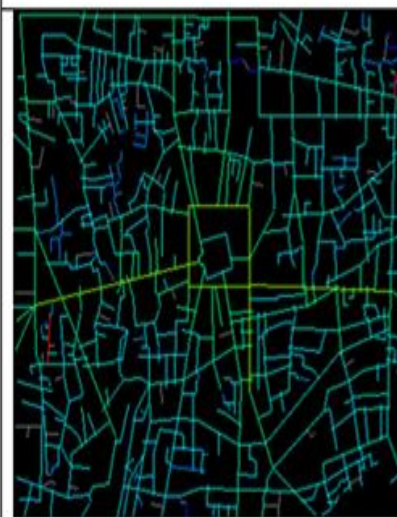

Existing Global Integration $\mathrm{Rn}$

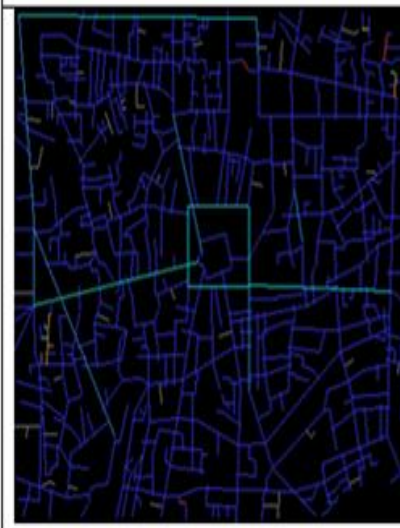

Existing NACH at 300 Radii

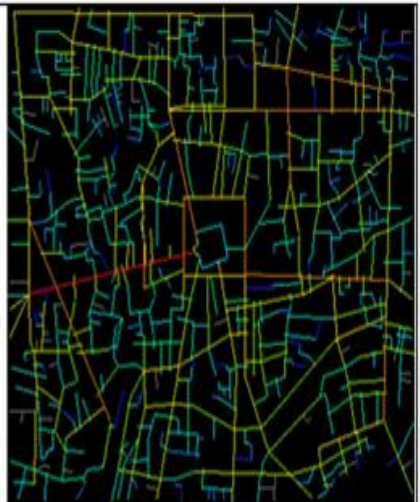

Local Integration $\mathrm{R} 3$ after Test 2

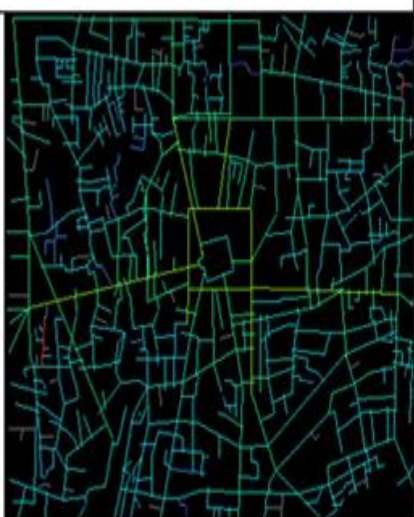

Global Integration $\mathrm{Rn}$ after Test 2

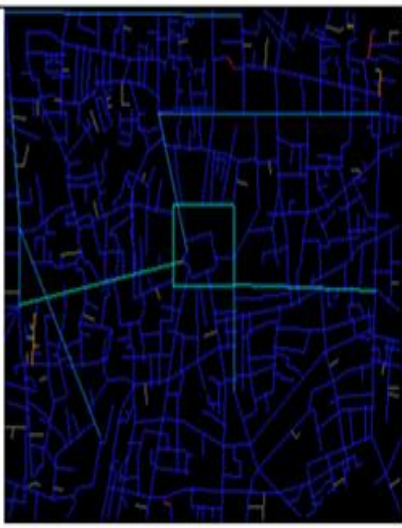

$\mathrm{NACH}$ at 300 Radii after Test 2

Fig 10: Axial map showing the syntactic parameters of Test 2

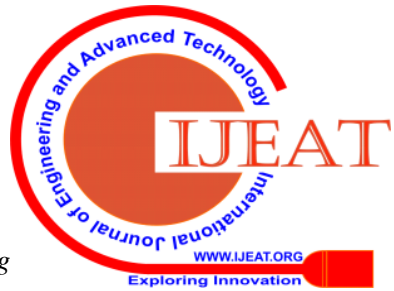


Table 3. Syntactic parameters showing A1>B

\begin{tabular}{|c|c|c|c|c|c|}
\hline & $\begin{array}{c}\text { Network } \\
\text { streets }\end{array}$ & & $\begin{array}{c}\text { Global } \\
\text { Integration } \\
\text { Rn } \\
\end{array}$ & $\begin{array}{c}\text { Local } \\
\text { Integration } \\
\text { R3 } \\
\end{array}$ & $\begin{array}{l}\text { NACH at } \\
300 \text { Radii }\end{array}$ \\
\hline \multirow{2}{*}{$\begin{array}{c}\text { Newly } \\
\text { added } \\
\text { networks }\end{array}$} & North Rd & \multirow[b]{2}{*}{ B } & 1.2198 & 2.5256 & 0.2012 \\
\hline & West Rd & & 1.1935 & 2.5489 & 0.0876 \\
\hline \multirow{7}{*}{$\begin{array}{c}\text { Existing } \\
\text { cultural } \\
\text { streets }\end{array}$} & M G Road & \multirow[b]{7}{*}{ A1 } & 1.3561 & 3.252 & 0.7177 \\
\hline & Round N & & 1.4277 & 2.6388 & 0.3704 \\
\hline & Round S & & 1.3681 & 2.5665 & 0.4451 \\
\hline & Round E & & 1.2541 & 2.6728 & 0.5241 \\
\hline & Round W & & 1.3689 & 2.8381 & 0.4458 \\
\hline & $\begin{array}{c}\text { Shornur } \\
\text { Road }\end{array}$ & & 1.3216 & 2.6526 & 0.3016 \\
\hline & High Road & & 1.2978 & 2.5885 & 0.2125 \\
\hline
\end{tabular}

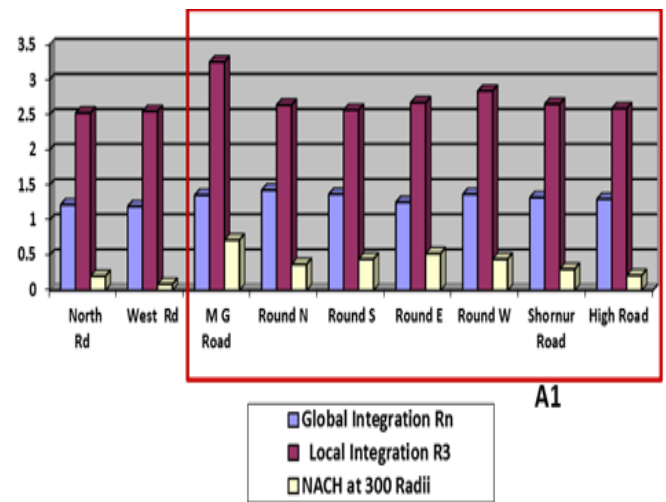

Fig 11. Syntactic parameters showing $\mathbf{B}<\mathbf{A 1}$

And also the existing high integration values of cultural street network has improved further from the existing values which is the case of A1>A is shown in fig 11 and also given in table 3 where the importance of the cultural integrity of the town is increasing further after the interventions.

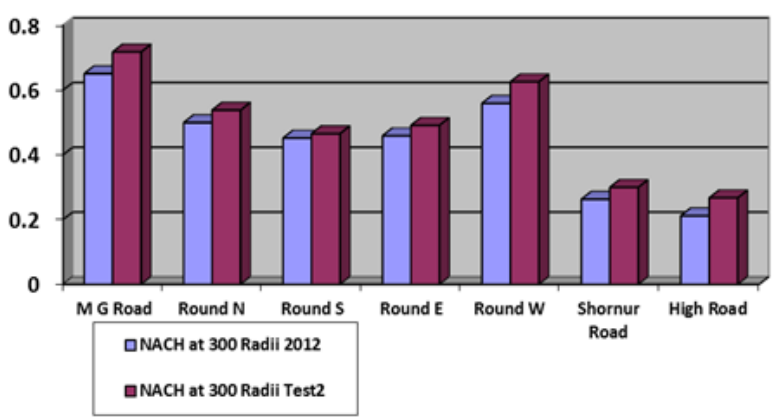

Fig 12. Comparative analysis of Normalised Angular Choice at Radii $\mathbf{3 0 0}$ Of major historic, cultural streets showing A1 $>$ A
The spatial positions of individual cultural routes with Angular radii 300 reflect their spatial relationships and

hierarchies in neighborhood, district, and city. Normalised angular choice in space syntax literature calculates the number of shortest paths overlap between all nodes in the graph and is implemented in depth map. Analytic experience of $\mathrm{NACH}$ suggests that high values indicate general thresholds for different types of activity to establish themselves in urban grids [3]. Test 2 clearly indicates that the Normalised Angular Choice of all the major historic cultural centers have increased from the existing values which improves the threshold for different cultural activities of the people for the cultural spaces in Thrissur.

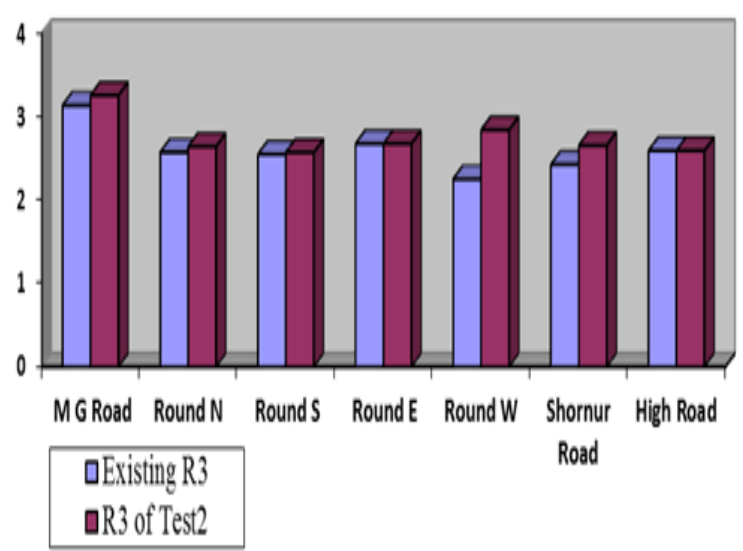

Fig 13. Comparative analysis of R3- Local Integration values of major historic, cultural street showing A1 $>A$ in Test 2 
Table 4. Syntactic parameters of Test 2 showing A1>A

\begin{tabular}{|c|c|c|c|c|c|c|c|c|}
\hline Syntactic & neters & M G Road & Round N & Round S & Round E & Round W & $\begin{array}{c}\text { Shornur } \\
\text { Road }\end{array}$ & High Road \\
\hline $\begin{array}{l}\text { Global } \\
\text { Integration } \\
\mathrm{Rn}\end{array}$ & \multirow[b]{3}{*}{ A } & 1.2912 & 1.3551 & 1.3446 & 1.3475 & 1.1889 & 1.1949 & 1.2739 \\
\hline $\begin{array}{l}\text { Local } \\
\text { Integration } \\
\text { R3 }\end{array}$ & & 3.1324 & 2.5706 & 2.5451 & 2.6729 & 2.2495 & 2.4225 & 2.5883 \\
\hline $\begin{array}{c}\text { NACH } \\
\text { At } 300 \\
\text { Radii }\end{array}$ & & 0.6507 & 0.4994 & 0.5591 & 0.4588 & 0.5811 & 0.2628 & 0.2117 \\
\hline $\begin{array}{c}\text { Global } \\
\text { Integration } \\
\text { Rn } \\
\end{array}$ & & 1.3561 & 1.4277 & 1.3681 & 1.2541 & 1.3689 & 1.3216 & 1.2978 \\
\hline $\begin{array}{c}\text { Local } \\
\text { Integration } \\
\text { R3 } \\
\end{array}$ & \multirow[b]{2}{*}{ A1 } & 3.252 & 2.6388 & 2.5665 & 2.6728 & 2.8381 & 2.6526 & 2.5885 \\
\hline $\begin{array}{c}\text { NACH } \\
\text { At } 300 \\
\text { Radii }\end{array}$ & & 0.7177 & 0.538 & 0.4654 & 0.4912 & 0.6257 & 0.2996 & 0.2672 \\
\hline
\end{tabular}

Table 4 Illustrates the increase in the configurational parametric values of all the cultural street networks of Thrissur after the model simulation by adding the heritage street connecting all the major urban artifacts of the temple town.

\section{RESULT ANALYSIS}

Test 1 clearly indicate that by adding new streets the local Integration Values of all the major historic, cultural centers have gone down from the existing values which reduces the culture specific user preference of the people for the cultural spaces in Thrissur.

Test 2 clearly indicates that by adding new streets the local Integration Values of all the major historic cultural centers have increased from the existing values which improves the culture specific user preference of the people for the cultural spaces in Thrissur.

\section{CONCLUSION}

The paper clearly proves that the proposed Space syntax model could be used as one of the best tools for urban interventions in the culturally integrated historic urban cores universally. During the process of understanding the culturally integrated urban cores of temple towns of Kerala, the urban intervention model evolved as a conceptual tool in these types of cities. The simulation of the model is done for only two cases in Thrissur town.

The conceptual model for urban interventions for culturally integrated historical cities proved to be successful with the two simulations. The first one is the case of adversely affecting the cultural integrity of the existing system whereas the second one is enhancing the cultural integrity of the town. This model can be applied in other culturally integrated cities as well. One can test the model for adding a new city centre, square, streets etc., The components of the model are limited only to the spatial configuration parameters applying space syntax theory. Other components like economy, traffic system, population, land use etc., are not taken into consideration since space syntax does not justify the same. The conceptual model can initiate a more proactive planning and urban design to be a more assimilating and generative, adaptive process that works in the interest of citizen's social aspirations rather than that of project developers or investors.

\section{REFERENCES}

1. M Alalhesabi1, S B Hosseini, F Nassabi.,'Housing visual quality in urban pattern, Application of isovist method in old fabric of Bushehr city", International Journal of Architectural Engineering \& Urban Planning, Vol. 22, No. 1, June 2012.

2. Bill Hillier Tao Yang, Alasdair Turner, "Normalising least angle choice in Depth map and how it opens up new perspectives on the global and local analysis of city space" The Journal of Space Syntax, Vol. 3, issue: 2, pp. 155-193, 2012.

3. Hillier B, "Centrality as a process: accounting for attraction inequalities in deformed grids", Urban Design International 1999, Vol. 4 (3 \&4), pp.107 - 127, 1999

\section{AUTHORS PROFILE}

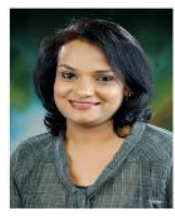

Dr. Josna Raphael. $\mathbf{P}$ is a Professor in Architecture at Government Engineering College,Thrissur ,Kerala,India. She has done her Bachelor's Degree in Architecture from College of Engineering Trivandrum, University of Kerala in 1996. Master's Degree in Architectural Conservation from SPA New Delhi in 1999 . And Ph.D. from NIT, Calicut in 2015. She has been teaching since 2000. Her Research Interests are Urban Conservation, Urban Design, Pedagogy in Design Teaching, Culture and Architecture, Space Syntax. These are few of the published Journals

\section{International Journa}

1. "Historic City of Kochi, symbiosis of conservation and development Kerala, India": International journal of World Academy of Science, Engineering \& Technology,Issue70,October2012

2. 'Social Logic of Morphological Evolution of Temple Towns of Kerala, India : Understanding the cultural influence on the spatial configuration of Temple Towns', International Journal of Chemical, Environmental and Biological Sciences (IJCEBS) ISSN 2320 -4079 (Printed Version) Vol. 5,May 2015

3. "The Integration of Tangible and Intangible Cultural heritage values for the Sustainable development of the cultural capital of Kerala: Thrissur, India" ,International Journal in Management \& Social Science (ISSN -2321-1784) Vol. 4,April 2015

Published By: 
4. "Understanding the cultural influence through space syntax on the spatial configuration of Temple Towns Of Kerala, India", International Journal in IT \& Engineering (ISSN-2321-1776) Vol. 4 ,April 2015

5. 'Understanding the Spatial Configuration of Traditional Temple Towns of Kerala', International Journal of Space Syntax, JOSS Vol. 6 (1),Spring/Summer 2015

6. Understanding the cultural influence through space syntax on the spatial configuration of Temple Towns of Kerala, India , Journal of Civil Engineering \& Environmental Technology(JCEET),Volume2,No.5, June 2015 